Aletria, Belo Horizonte, v. 29, n. 1, p. 73-89, 2019

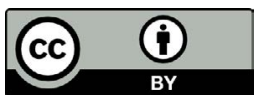

\title{
Tempo e drama: do presente absoluto à simultaneidade de temporalidades
}

\section{Time and Drama: From the Absolute Present Tense to the Simultaneity of Temporalities}

\author{
Rodrigo Alves do Nascimento \\ Universidade de São Paulo, São Paulo, São Paulo / Brasil \\ professor.rodrigonascimento@gmail.com \\ Bruno Barretto Gomide \\ Universidade de São Paulo, São Paulo, São Paulo / Brasil \\ bgomide@usp.br
}

Resumo: Na virada do século XIX para o século XX emergiu um tipo de dramaturgia na qual a experiência temporal dos personagens passava a ser elemento temático decisivo. Do mesmo modo, o próprio tempo se tornava um problema formal, visível e produtivo. Tal processo é patente nas peças de Ibsen, Maeterlinck e Strindberg, que romperam com a tradição neoclássica, então pautada por uma temporalidade discreta, quase invisível, em que o drama e a própria representação cênica se fechavam à experiência de um presente absoluto. Dentro desse impulso de renovação, as peças de Tchékhov - em especial As Três Irmãs - tiveram papel crucial. Como veremos, elas acomodaram na tessitura dramática uma simultaneidade de temporalidades, levaram o realismo ao seu limite e desestabilizaram a própria relação entre o tempo do texto e o tempo da cena.

Palavras-chave: tempo; drama; Anton Tchékhov; As Três Irmãs.

Abstract: At the turn of the twentieth century a new form of dramaturgy emerged in which the characters' temporal experience became a decisive thematic element. Likewise, time itself became a formal problem that was both visible and productive. Such a process is evident in Ibsen's, Maeterlinck's and Strindberg's plays, which led to decisive breakthroughs in the neoclassical theater tradition guided by a temporality 
in which drama and scenic representation were enclosed to the experience of an absolute present. Within this impulse of renewal, Anton Chekhov's plays - The Three Sisters in particular - had a crucial role. As we shall see, these plays accommodated simultaneity of temporalities in their dramatic threat. Furthermore, such pieces also brought realism to its limits and destabilized the very relation between the time of the text and the time of the scene.

Keywords: time; drama; Anton Chekhov; The Three Sisters.

O teatro é uma linguagem e uma atividade que sugere uma relação diversa do ser humano com o tempo. Diferentemente do cinema, do vídeo, da música e da literatura, capazes de serem reproduzidos e consumidos em diferentes momentos e contextos, ele se baseia em um aqui e agora compartilhado com o público. A própria ritualização comum das casas teatrais tradicionais - ou mesmo do teatro de rua - demanda uma preparação para a experiência de uma outra temporalidade: o bumbo que reúne os transeuntes apressados para a apresentação teatral na praça, os encontros e conversas amenas no saguão do teatro, a entrada lenta na sala e os três toques que anunciam o início do espetáculo. Logo de início, é como se o espectador fosse introduzido em uma temporalidade distinta daquela que moveu sua saída apressada de casa, sua corrida para tomar o ônibus ou o táxi, ou sua angústia para responder à última mensagem no celular. Em suma, uma experiência temporal diferente daquela que pauta as relações modernas aceleradas. Talvez como resistência, o teatro ainda insista em dizer: meu tempo é outro. Anne Ubersfeld concebe tal processo de passagem de um tempo social a um tempo dramático como um "tempo iniciático". ${ }^{1}$ Sem essa outra temporalidade, uma integração com o fenômeno teatral seria impossível ou, no mínimo, menos intensa.

No entanto, ainda que o teatro logo de saída busque negociar outros sentidos possíveis para a experiência temporal, a relação entre tempo, teatro e dramaturgia é pouco discutida. Em primeiro lugar, porque na dramaturgia os elementos temporais são em geral vagos e indiretos. Consistem de rubricas que demarcam um período do dia, uma passagem ou um intervalo de tempo. Na representação teatral, do mesmo modo, eles são menos perceptíveis que os elementos espaço-visuais,

${ }^{1}$ UBERSFELD. L'École du Spectateur, p. 240-241. Tradução nossa. 
pois diluem-se nas pausas, ritmos e cortes. Ou seja, objetivamente, o dispositivo temporal parece muito mais elusivo e passível de múltiplas e simultâneas significações, além de ser significado a partir da interferência de sentidos maiores: "imagem do tempo da história, do tempo psíquico individual, do retorno cerimonial", etc. ${ }^{2}$ Isso significa que, do ponto de vista estrutural, sua apreensão e análise tornam-se muito dificultadas. E mesmo no campo da análise filosófica, o conceito de tempo emerge como um dos mais polêmicos e problemáticos, justamente porque de difícil definição e sempre pensado em relação a outros componentes que o qualificam: o espaço, o movimento ou a experiência. De qualquer modo, não negada a complexidade de tal relação, o que se percebe é que os séculos XX e XXI tornaram o tempo tema funtadamental e instalaram-no de maneira explícita na própria tessitura dramatúrgica, tornando evidente a constatação de que ele seria nossa dimensão existencial mais básica, ${ }^{3}$ ou ainda, "o tecido da nossa vida". 4

$\mathrm{O}$ primeiro grande impulso de tal processo se deu em meados do século XIX e tem a ver com mudanças importantes nas formas de sociabilidade do mundo moderno - a experiência do isolamento, da carência urbana crescente, das guerras e genocídios -, que abriram as formas artísticas para as temporalidades do trauma, da melancolia, das frustrações, do sonho e mesmo das revoluções. Isso produziu um questionamento direto das formas fechadas que regeram toda uma poética do drama e das práticas teatrais até meados do XIX, nas quais o encadeamento lógico da ação (concepção organicista da peça de teatro) e uma distorcida unidade de espaço e, em especial, de tempo, predominavam.

\section{Temporalidade única: o presente absoluto}

Do século XVII até meados do século XIX prevaleceu, em boa parte das formas dramáticas e das teorias teatrais europeias, a doxa neoclássica, segundo a qual, dentre outras coisas, o bom espetáculo seria aquele que conseguisse aproximar as duas temporalidades que marcam o fenômeno cênico: a da representação e a da ação representada. $\mathrm{O}$ tempo

\footnotetext{
${ }^{2}$ UBERSFELD. Para ler o teatro, p. 126.

${ }^{3}$ PRIGOGINE. The End of Certainty, p. 13.

${ }^{4}$ CANDIDO apud GLASS. Antonio Candido inaugura biblioteca do MST e fala da força da instrução. Carta Maior.
} 
cronometrado deveria coincidir ao máximo com o tempo ficcional e subjetivo. Teatro e texto dramatúrgico eram então concebidos dentro de uma mesma lógica. Desse modo, um espectador que estivesse na sala de espetáculo por três horas deveria ter a sensação de que a fábula apresentada também não durou muito além disso. Esta formulação emergiu de modo decisivo com as leituras da Poética de Aristóteles feitas por Ludovico Castelvetro (1505-1571). Ele seria responsável por implementar a partir das ideias do filósofo grego a regra das unidades de lugar e de tempo, que passariam a funcionar como critérios de julgamento para os dramaturgos de então. Quanto mais a duração da ação ficcional se aproximasse da duração da representação experimentada pelo público, maior chance de conquista da verossimilhança.

Mais tarde, Jean Chapelain (1595-1674) passou a enfatizar a superioridade do modelo aristotélico e iniciou um movimento dogmático de implantação do realismo no teatro. As bases de tal realismo não eram um mimetismo fotográfico, mas o esforço pela construção do inteligível. Estava aí a base de uma verossimilhança que se baseava na ideia de que a capacidade de assimilação do espectador era limitada, de modo que grandes deslocamentos de espaço e a passagem de longos períodos de tempo, modelados dentro de uma representação de três horas em um espaço restrito (o teatro), gerariam ruídos de imersão, pois o espectador imediatamente quebraria a ilusão do palco para refletir sobre o tempo que passou fora de cena.

Aristóteles, no entanto, não havia chegado a este grau de detalhamento. Afirmava que a tragédia deveria evitar a forma da epopeia, ou seja, evitar a apresentação de uma multiplicidade de fábulas, como na Ilíada. ${ }^{5}$ Isso porque tal forma múltipla não só dificultaria a apresentação de uma ação concentrada, com começo, meio e fim nítidos, mas também porque exigiria um malabarismo teatral que justificasse a passagem de longos períodos de tempo: “[...] a tragédia, tanto quanto possível, procura caber dentro de uma revolução do sol ou ultrapassá-la um pouco; na epopeia, a duração não tem limitações, e nisso ambas diferem."

\footnotetext{
${ }^{5}$ ARISTÓTELES. Poética. Organon. Política. Constituição de Atenas, p. 60.

${ }^{6}$ No entanto, Aristóteles reconhece que esta forma específica de lidar com o tempo na tragédia se deu menos por princípio e mais pela prática: “[...] no começo, o tempo da tragédia era ilimitado, como sucedia também nas epopeias". Ao mesmo tempo, nas próprias competições teatrais do período, as tragédias que apresentassem muitas
} 
Seu foco, como se sabe, estava nas formulações a respeito da tragédia como imitação das ações humanas, sendo sua intriga composta não pela revelação de toda a trajetória de um indivíduo, mas a escolha de um período em que "se dá a mudança que leva à felicidade ou ao infortúnio" e seu desfecho, aquilo que "vai do começo da mudança ao final da peça".

Com exceção de tais passagens, Aristóteles praticamente não se dedicou às considerações sobre a forma do tempo na tragédia. De qualquer modo, o neoclassicismo francês as transformou em uma regra de unidade temporal (operada em conjunto com as unidades de espaço e ação), convertendo a ideia de "revolução do sol" em verdadeira questão exegética. Afinal, o tempo útil da tragédia seria apenas as doze horas entre o nascer e o pôr do sol ou esta revolução comportaria também a volta que o sol faz à noite? Não seria também a noite palco de acontecimentos dignos de nota?

De início, prevaleceu entre os neoclássicos a doutrina do "dia artificial" que, segundo Chapelain seria aquele mais ou menos equivalente às doze horas do dia. Desse modo, a "homologia exata das duas temporalidades" (da representação e do representado), tornava-se um imperativo. ${ }^{8} \mathrm{Na}$ incapacidade de realizar tal feito, malabarismos eram necessários, mas deveriam ser feitos com o máximo de sutileza e moderação. De todo modo, o que tais discussões a respeito da preferência pelo dia natural ou o dia artificial revelam é que os neoclássicos se enredaram em uma seara totalmente arbitrária. Afinal, os dramaturgos anteriores à fixação de tal doxa estabeleciam em suas peças uma temporalidade que atendesse, exclusivamente, às demandas da ação, sem a coerção de uma falsa unidade. Muitos, em debate com os neoclássicos, problematizavam:

fábulas e longos períodos de tempo tendiam a ser mal avaliadas: "Demonstram-nos os poetas que pretenderam colocar numa só tragédia a história inteira da Ruína de Troia (e não, como fez Eurípedes, uma única parte) ou de Níobe (ao contrário do que fez Ésquilo). Fracassaram todos eles, ou obtiveram má classificação nos concursos [...]". (ARISTÓTELES. Poética. Organon. Política. Constituição de Atenas, p. 60).

${ }^{7}$ ROUBINE. Introdução às Grandes Teorias do Teatro, p. 42-59.

${ }^{8}$ Mais tarde, como aponta Jean-Jaques Roubine, a segunda geração clássica aceitaria a possibilidade de fábulas que abarcassem os acontecimentos no decurso de vinte e quatro horas. Mesmo Corneille, que depois da querela do Cid evitou ao máximo a escrita de peças com fábulas que ultrapassassem as vinte e quatro horas do "dia natural", advogou em favor da possibilidade de fábulas com trinta horas. ROUBINE. Introdução às Grandes Teorias do Teatro. 
se é inverossível 'representar' em algumas horas uma ação que, manifestamente, precisa se estender por vários meses ou anos, não o é também querer encaixar em doze ou vinte e quatro horas acontecimentos que requerem, claramente, mais tempo para se realizar ou se encadear uns aos outros? ${ }^{9}$

Não à toa, muitos neoclássicos seriam totalmente avessos à dramaturgia shakespeariana, na qual o tempo dramático é muito mais longo que o tempo da representação, já que, por vezes, anos se passam entre um ato e outro.

Se por um lado tal normatividade trazia facilidades de produção, como uma demanda menor por mudança de cenários, de figurinos ou de aspecto físico (envelhecimento do personagem, por exemplo), a questão é que ela modula um tipo de experiência temporal muito específica. Em primeiro lugar, leva a uma construção fechada na qual o tempo da representação tende a uma desmaterialização. Ou seja, o tempo e sua passagem só podem ser percebidos por meio da presença do personagem que os verbaliza por meio do diálogo. $\mathrm{O}$ espectador percebe que algo aconteceu há alguns minutos, que algo acontece na sala ao lado ou que algo pode acontecer no futuro pela presença de um conjunto de referentes mencionados no discurso do personagem. É ele quem filtra a experiência temporal e cria a ilusão de "uma fala pura, de um discurso onde coincidem o mundo e a personagem simbolizada, seu discurso presente e sua existência fictícia exterior". ${ }^{10}$

Desse modo, estabelece-se o império da ação concentrada com tempo lógico-causal, que culminará em meados do século XIX na peça benfeita de Eugène Scribe. ${ }^{11}$ Nela, o que vale é a apresentação de um acontecimento excepcional, construído em torno de surpresas espetaculares (cartas misteriosas, tiros, escutas atrás da porta, etc.) e de uma cena fundamental para a qual todas as demais se encaminham (a resolução do nó do conflito, a cena a ser feita). Ou seja, estabelece-se

\footnotetext{
${ }^{9}$ ROUBINE. Introdução às Grandes Teorias do Teatro, p. 46.

${ }^{10}$ PAVIS. Dicionário de Teatro, p. 402.

${ }^{11}$ Patrice Pavis vai além e afirma que este tipo de dramaturgia fechada teria influência não só em dramaturgos pós-clássicos, como Marivaux e Voltaire, como também em formas dramáticas do século XX, como a comédia de boulevard e a telenovela. PAVIS. Dicionário de Teatro, p. 115.
} 
um tempo altamente racionalizado, baseado na dinâmica preparaçãorealização. Günter Müller e Peter Pütz demonstraram, dentro de uma perspectiva estrutural, o quanto essa dinâmica seria fundamental para o estabelecimento de uma determinada perspectiva temporal, na qual o suspense da preparação tem efeito estético decisivo. ${ }^{12}$

Ademais, a forma dramática se fecha para outras experiências temporais. Até meados do século XIX, muitas possibilidades de instalação de outras temporalidades na tessitura dramática e teatral já tinham sido experimentadas ou estavam em franco desenvolvimento no teatro Europeu, com inquestionável popularidade. No entanto, para os neoclássicos, esta multiplicidade de temporalidades seria não só trabalhosa do ponto de vista da produção, mas inverossímil, pois demandaria artificiais recursos de teatralização. Assim, procedimentos épicos, como a personagem shakespereana que narra acontecimentos passados, a cena simultânea do teatro medieval (que colocava lado a lado diferentes carros com os diferentes cenários - e por isso sugeria de algum modo a própria simultaneidade de temporalidades que habitam o fenômeno teatral), ${ }^{13}$ e mesmo o uso constante de prólogos, epílogos e monólogos pelo teatro Barroco, que apresentava uma voz externa capaz de organizar as demais e sugerir uma temporalidade suspensa (o tempo do mundo é caótico, fugaz e enganador), eram mal-vistas pelas vozes autorizadas da doxa.

Por fim, tal normatividade gerava um último resultado: a instalação de um presente absoluto no drama. Inicialmente, ele pode ser definido nos termos de uma lógica de diferentes "presentes" - identificando-se assim com os "presentes sucessivos" que marcam a experiência temporal do próprio espectador na plateia; mas dessa construção deriva também uma espécie de presente ideológico absoluto, que não concebe uma temporalidade outra que não aquela que aposta na ação do indivíduo consciente de si no aqui e agora. Esta sequência lógica de presentes

${ }^{12}$ STEWART. Time Structure in Drama: Goethe's Sturm Und Drang Plays, p. 12-14.

${ }_{13}$ Anatol Rosenfeld demonstra como, nesse período, esta concepção de uma temporalidade sucessiva (dos palcos simultâneos que já estão lá em situação de "repouso", simultaneamente, e depois se organizam em uma lógica sucessiva) era afim às formulações de Santo Agostinho a respeito do tempo: "A eternidade divina é atemporalidade em que o 'então' das origens coincide com o 'então' escatológico. O palco simultâneo é a manifestação da essência, sobrepondo-se à aparência sucessiva". ROSENFELD. O Teatro Épico, p. 49. 
depende essencialmente do diálogo intersubjetivo, o qual funciona como espelho das relações humanas e, por isso, desligado de qualquer voz, relação ou temporalidade que lhe seja externa.

Esse caráter primário do drama, ou seja, o fato de que ele representa a si mesmo e não a algo que lhe seja externo, faz com que sua época seja sempre o presente: ele "passa e se torna passado, mas enquanto tal já não está mais presente em cena. Ele passa produzindo uma mudança, nascendo um novo presente de sua antítese [...] ele funda seu próprio tempo." ${ }^{14}$ Nessa lógica, em que uma cena prepara a outra, em que uma fala engendra sua resposta e empurra a máquina dramática adiante, qualquer voz externa (o monólogo, o aparte, o prólogo, o epílogo ou o coro) representa não só a quebra da verossimilhança (e, por tabela, da ilusão dramática), mas sobretudo de uma determinada temporalidade: a quebra do presente absoluto que não precisa refletir sobre si, pois não possui elemento que lhe sirva de contraponto ou o relativize. Assim, temse também um campo temático restritivo: não há espaço para balanços sobre passado, para lamentações sobre a vida presente, para longas reflexões sobre o futuro ou para as projeções do sonho; não há espaço para crises existenciais do sujeito ou relativização de sua capacidade de viver o tempo presente. O tempo presente é diálogo e é ação.

O substrato ideológico de tal empreitada parece evidente: seja na forma do drama burguês, seja nas formas do melodrama e mesmo do vaudeville francês, há o elogio da atividade humana positiva por meio do diálogo, o elogio da vontade livre e consciente do indivíduo. Ou seja, fecha-se o espaço do drama para a multiplicidade de temporalidades que habita o espaço público e seus grandes conflitos e conforma-se a ação à temporalidade heroica e edificante da casa burguesa patriarcal, pensada como "o lugar da felicidade possível". ${ }^{15}$ Ora, no caso específico do drama burguês, tal percepção está em sintonia com a presumida universalidade otimista das Luzes - o presente é prenhe de possibilidades positivas porque é o palco da emancipação do indivíduo livre, seja ele apresentado inicialmente como a alma enclausurada, enganada ou combatida pelas forças retrógradas. O presente absoluto do lar, edificante e modelar, é seu ponto de partida.

\footnotetext{
${ }^{14}$ SZONDI. Teoria do Drama Moderno, p. 32.

${ }^{15}$ Prefácio de Sérgio de Carvalho ao livro de SZONDI. Teoria do Drama Burguês, p. 12-13.
} 


\section{Novo drama, novo tempo: As Três Irmãs e a simultaneidade de temporalidades}

Os românticos fariam um enfrentamento direto a essa temporalidade única ao insistirem na ideia de resgate de uma "cor local". Para eles, a estilização do drama neoclássico seria uma camisa de força contra as temporalidades inerentes às formações socioculturais de cada povo. Ao mesmo tempo, um motivo romântico poderoso seria o da experiência subjetiva despedaçada, do deslocamento e da inadequação às normas sociais. Tem-se aí um prato cheio para a mistura das temporalidades reivindicadas pelas diferentes subjetividades e pelos diferentes gêneros literários. Assim o faria Ludwig Tieck (1773-1853), ao retrabalhar formas dramáticas e convenções do teatro em seu $O$ Gato de Botas, desestabilizando a concepção dominante da peça equilibrada, orgânica e fechada em um presente absoluto. De maneira mais programática e aberta, Victor Hugo faria no seu prefácio a Cromwell um enfrentamento da regra das três unidades, tendo Shakespeare à frente como modelo, dada a capacidade do bardo de plasmar gêneros e temporalidades, sendo criador de uma atmosfera muito mais verossímil, emocional e catártica do que os epígonos dos quais Aristóteles reivindicavam serem capazes. ${ }^{16}$

Ainda assim, o intermezzo romântico não foi capaz de desestabilizar, de todo, o império dramático do "belo animal". Ao longo do século XIX, a peça benfeita seria nota dominante dos palcos da França aos palcos da Rússia (ainda que tenha tido menor penetração nos países germânicos e na Inglaterra), funcionando como base formal para a maioria dos dramas, melodramas e vaudevilles em cartaz. Essa forma dramática substancializada, comparável a um ser vivo uno (Aristóteles se referia à tragédia um corpo orgânico, com começo, meio e fim), começa já a partir de meados do século XIX, a sofrer abalos estruturais. Este drama moderno se abrirá irresistivelmente a uma hibridização de formas e temporalidades. ${ }^{17}$

O impulso por trás de tal processo é a crise do presente universalizante burguês, que precisa lidar com visões de mundo consistentes e alternativas à sua, bem como com a emergência de um descontentamento generalizado com seu otimismo idealista. "O drama sempre produz uma imagem da interação do homem no tempo", diria

${ }^{16}$ ROSENFELD. O Teatro Épico, p. 73.

${ }^{17}$ KUNTZ, H. Belo animal (morte do), p. 41-43. 
Jackson Barry, ${ }^{18} \mathrm{e}$ Buchner seria um dos primeiros no século XIX a trazer a percepção de uma outra temporalidade a reger a tessitura dramatúrgica. Em seu Morte de Danton, o personsagem se sente aniquilado pelo fatalismo da história que o esmaga - o oposto daquele sujeito outrora empoderado, dono de seu presente.

Do mesmo modo, os personagens de Henrik Ibsen (1828-1906) se voltarão insistentemente para o passado. Em suas peças, o lar edificante tornou-se espaço de opressão e sufocamento. As memórias se instalam em um presente morto e tornam-se tema: o passado assim é evocado não somente na forma de pequenos acontecimentos recordados, mas como experiência geral. Ele está em bloco na hereditariedade da sífilis que subjaz à fábula de Espectros, bem como no conjunto de decisões tomadas por Nora para salvar seu marido, em Casa de Bonecas, com as quais agora contrapõe ao presente de um casamento sem sentido - tudo isso matéria de difícil elaboração em uma forma que até então apostava num diálogo no presente como motor da ação.

Assim também em August Strindberg (1849-1912), com seu drama subjetivo ou com seus dramas de estações: a forma dramática se coloca a serviço da representação de acontecimentos psíquicos, memórias e projeções com temporalidade distendida, a qual não se propõe em nenhum momento a corresponder à passagem do tempo em termos racionais ou cronológicos. Na mesma esteira, Maurice Maeterlinck (18621949) dá projeção ao sujeito que se vê diante das imposições do destino. Substitui a categoria de ação pela de situação, na qual o homem persiste até seu contato com a consciência inevitável da morte. O tempo, seja o da temporalidade cíclica da natureza, seja o da temporalidade moderna do relógio, dilue-se no caráter absoluto da Eternidade. Não à toa, em $O s$ Cegos, a ação se passa em uma "antiquíssima floresta setentrional, de aspecto eterno sob um céu profundamente estrelado". ${ }^{19}$

\footnotetext{
${ }^{18}$ BARRY. Dramatic Structure: the shaping of experience, p. 10.

19 "SEGUNDO CEGO DE NASCENÇA: Estamos no sol, agora?

TERCEIRO CEGO DE NASCENÇA: Ainda tem sol?

O SEXTO CEGO: Acho que não; parece que já é tarde.

SEGUNDO CEGO DE NASCENÇA: Que horas são?

OS OUTROS CEGOS: Não sei. - Ninguém sabe.”

MAETERLINCK. Os Cegos, p. 3-11. Manuscrito não publicado.
} 
No entanto, dentro desse movimento de questionamento das formas dramáticas neoclássicas e seu substrato temporal homogêneo, é com o dramaturgo russo Anton Tchékhov que a ruptura se dá de modo mais evidente: do drama tradicional restará apenas uma estrutura aparente, já que o presente absoluto é posto em questão e a tessitura dramatúrgica se abre para uma multiplicidade de temporalidades (a da espera, da memória, do desejo, do remorso, do sonho, etc.). Isso fica evidente, sobretudo, em suas peças longas. Em Ivánov, ${ }^{20}$ de 1887, o presente do personagem Nikolai Alekséievitch é acachapante. Inábil para lidar com seu próprio tempo, não consegue agir e a única solução que encontra é uma espécie de inércia que culmina no suicídio. Na mesma direção, em A Gaivota, de 1896, a personagem Arkádina, atriz de sucesso no passado, vive da lembrança de sua glória, arrastando-se artificialmente no presente. Enquanto isso, seu jovem filho Trepliov projeta para si um futuro glorioso como dramaturgo, mas depende da aprovação afetiva do maior símbolo de um teatro "ultrapassado": sua própria mãe. Ao mesmo tempo, a personagem Nina, a quem Triepliev ama incondicionalmente, sonha com um futuro brilhante como atriz, longe do presente doloroso representado pela sua vida limitada no campo. Ao final, volta arrasada, com o peso de um passado de dor e frustração. ${ }^{21}$ Já em Tio Vânia, de 1889, o personagem Serebriákov, professor universitário aposentado e cunhado de Vânia, lamenta um presente miserável, no qual tem a sensação de que seu mérito intelectual já nada vale e seu corpo é uma fonte inesgotável de dores. E Vânia, entregue desde jovem ao trabalho para a família na propriedade de província, percebe, junto à sobrinha Sônia, que a vida atual é opressão e que todo um passado de serviços e dedicação foi reduzido à ingratidão familiar e amorosa. ${ }^{22}$

Em As Três Irmãss, ${ }^{23}$ peça de 1902, a angústia em relação ao tempo vivido (e a própria angústia da forma em relação a um tempo dramático fechado) emerge de modo exemplar. O primeiro contato com esse "drama em quatro atos" já revela um conjunto de símbolos e referências diretas a marcas de temporalidade e de passagem do tempo. Da personagem Olga sabemos, logo na primeira fala do primeiro ato, que é cinco de maio,

\footnotetext{
${ }^{20}$ TCHÉKHOV. Ivánov.

${ }^{21}$ TCHÉKHOV. A Gaivota.

${ }^{22}$ TCHÉKHOV. A Gaivota / Tio Vânia.

${ }^{23}$ TCHÉKHOV. As Três Irmãs/ O Jardim das Cerejeiras.
} 
primavera, e que sua irmã, Irina, completa vinte anos. É meio dia (o relógio badala). Estão há um ano da morte do pai e há onze anos distantes de Moscou. As personagens se reúnem para o almoço e mencionam suas idades e o quanto envelheceram (a barriga de Andrei que aumentou, a aparência envelhecida de Verchínin). Falam da promessa futura de Andrei como intelectual e Irina ganha um velho samovar de presente do senil Tchebutykin. No segundo ato, a rubrica indica que é inverno e são oito da noite de um dia de fevereiro. Aproximadamente dois anos se passaram em relação ao ato anterior, pois a cunhada das irmãs, Natacha, agora mora na casa de seu esposo, Andrei, e os dois têm um filho. Andrei não se tornou professor universitário, como almejava no primeiro ato e agora trabalha na repartição com Protopópov, possível amante de Natacha. Irina também começou a trabalhar no correio, está cansada e com semblante completamente diverso do primeiro ato. $\mathrm{O}$ terceiro ato ocorre de madrugada, entre duas e quatro horas e provavelmente é verão, já que amanhece cedo. Estão há, aproximadamente, um ano do segundo ato, pois Irina tem 23 anos e Natacha já tem um segundo filho. Irina agora trabalha na prefeitura e aceita a sugestão de Olga de que deve se casar com o velho Tuzenbach. Recebem a notícia de que os militares serão transferidos para outra cidade, depois de alguns anos ali instalados. Já o último ato ocorre por volta de um meio dia de outono, é dia da partida do primeiro grupo de militares. Olga já não mora na casa e agora vive na escola, onde é diretora. O agora reconhecido amante de Natacha, Protopópov, visita a casa e provavelmente é o pai da nova criança. ${ }^{24}$ Além das referências diretas à passagem do tempo nos marcadores de cena, a todo momento as personagens fazem referência ao cansaço, à falta de sentido da vida, ao tédio do presente. Do mesmo modo, rememoram insistentemente a Moscou de onze anos atrás, para onde querem voltar, e filosofam sobre o futuro, questionando-se se serão lembradas ou não pelas próximas gerações. A presença do tempo é tão palpável que é como se ele tivesse se condensado em um objeto sólido no centro da sala ou do jardim das irmãs.

\footnotetext{
${ }^{24} \mathrm{C}$. Turner faz levantamento exaustivo e detalhado da presença de elementos que marcam o tempo e sua passagem ao longo de As Três Irmãs. Segundo ele, pode-se dizer que, ao todo, quatro anos e meio se passaram entre o primeiro e o último ato. TURNER, C. J. G. Time in Chekhov's Tri Sestry. Canadian Slavonic Papers. Vol. 28., mar. 1986, p. 64-79.
} 
À primeira vista, percebe-se na fala dos personagens uma espécie de discurso sobre a experiência temporal, e é como se as referências insistentes ao tempo cíclico da natureza, ao tempo cronológico do relógio, aos aniversários e às datas fossem uma tentativa de captura de uma experiência vital perdida. Estas referências vão compondo uma superfície enganosa, semelhante a um enorme falatório sem sentido, que Tchékhov constantemente ironiza na forma do próprio drama. $\mathrm{E}$ o dramaturgo o faz por meio de três recursos formais fundamentais: o esvaziamento dos diálogos entre as personagens, a redefinição da noção de evento e a implementação de constantes momentos de estase.

Em primeiro lugar, o diálogo tradicional perde sua função organizadora ao ser recheado de contrapontos indiretos, citações descoladas e solilóquios existenciais. No primeiro ato, quando Olga fala com as irmãs sobre Moscou e sobre seu desejo de voltar para sua cidade natal, Tchebutykin e Tuzenbach entram na sala conversando entre si, mas o resto da conversa entre ambos a interrompe: "Tchebutykin: Que nada!/ Tuzenbach: Claro, que bobagem!". ${ }^{25}$ Olga obviamente não toma o contraponto como uma resposta ao que ela dizia, mas o espectador inevitavelmente entenderá o artifício tchekhoviano como uma ironia ao desejo de voltar à antiga Moscou. O mesmo ocorre no segundo ato, quando Irina afirma com veemência que irá para Moscou e Fedotik, referindo-se ao jogo, diz: "Não, não vai dar certo, veja, o oito está sobre o dois de espadas. (Ri.) Portanto, não irão para Moscou" ${ }^{26}$ Do mesmo modo, abundam na peça momentos em que o diálogo perde sua força no presente ao ser recheado de citações que beiram o nonsense e demonstram o quanto os personagens estão atados a um passado e a fórmulas tradicionais de vida. ${ }^{27}$ Por fim, quando Tchékhov finalmente cria uma cena na qual Andrei se abre a Ferapont e revela todas suas frustrações e desejos, o diálogo resulta impossível: o velho contínuo da municipalidade é surdo. Assim, ao esvaziar o diálogo que no drama tradicional tinha papel central, Tchékhov tira a própria possibilidade do presente ser convertido em tecido temporal absoluto.

O segundo procedimento é a redefinição da noção tradicional de "evento" (ou "acontecimento"). A peça benfeita, como vimos, se

\footnotetext{
${ }^{25}$ TCHÉKHOV. As Três Irmãs/ O Jardim das Cerejeiras, p. 8.

${ }^{26}$ TCHÉKHOV. As Três Irmãs/ O Jardim das Cerejeiras, p. 32

${ }^{27}$ KATÁEV. If Only We Could Know, p. 258.
} 
estruturava em torno de um acontecimento excepcional, para o qual todas as cenas secundárias se encaminhavam. Tchékhov prefere dar proeminência a eventos de outra natureza. Não mais duelos, cenas clássicas de traição ou o embate direto entre duas forças antagônicas onstage -, pois tudo isso tudo passa a acontecer nos bastidores - offstage. Ao invés de um conflito claro no presente, em As Três Irmãs, há o reverso: Olga e Irina são absorvidas pelo fluxo de um trabalho sem sentido, Macha sofre com um casamento morto e Andrei vai sendo arrastado pelo jogo e pelas frustrações com o casamento. A tensão é dissolvida no íntimo dos personagens (a fábula dura mais de um ano!) e, ao esvaziar o drama do acontecimento tradicional, o dramaturgo expõe uma experiência temporal diversa, mais ligada à temporalidade fluida do cotidiano, das frustrações, da melancolia e das lamentações.

No entanto, o modo como os personagens experimentam essas temporalidades é mais complexo do que a entrega passiva e tediosa a um presente vazio. Se suas declarações sobre o futuro são enganosas, Tchékhov introduz uma série de momentos de estase que se sugerem, não uma intensificação do tédio (como, erroneamente, muitos diretores teatrais interpretaram as peças do dramaturgo), mas uma suspensão do próprio fluxo do tempo. Nestes momentos, os movimentos são deliberadamente desacelerados e o tempo parece ganhar uma dimensão sólida. Não à toa, a peça indica um total de 63 pausas nas rubricas. Além disso, na cena inicial, o dramaturgo insere um relógio batendo meio dia (12 badaladas indicam uma pausa longa que, se levada à cabo, é um desafio para qualquer encenação, do seu tempo estendido). Além disso, há cenas constantes em que o fluxo do tempo parece se interromper: no último ato, quando todos se "congelam" para tirar uma foto ou mesmo no terceiro ato quando olham longamente para um relógio quebrado por Tchebutykin. Tais momentos sugerem uma desautomatização da existência e conectam os personagens a uma temporalidade profunda. Não há discurso, nem gesto artificial, apenas um momento de estase. Ali, distantes da lógica ágil da peça benfeita, os personagens estão mais próximos da durée bergsoniana, ou seja, de uma experiência temporal não enquadrável nas categorias espacializadas do tempo moderno cronometrado pelo relógio.

Desse modo, ao quebrar a dinâmica tradicional do diálogo, da noção de evento e mesmo da relação entre o tempo do texto e o tempo da cena que caracterizaram a dramaturgia anterior, Tchékhov dá lugar a um 
movimento subliminar, em que interessam os interditos de temporalidades não lógicas. A coesão temporal pautada por um presente absoluto da fábula e da ação cênica perde seu sentido e é a própria "simultaneidade de temporalidades" que se torna elemento estruturante. ${ }^{28}$

O substrato por trás de tal construção habilmente arquitetada pelo dramaturgo russo é a resistência à temporalidade positiva Ocidentalliberal, que aposta no presente homogêneo, linear e absoluto. Desse modo, as peças longas de Tchékhov, mormente As Três Irmãs, revelam em um só golpe o potencial crítico por trás dos clichês da inação e do tédio: o lar e o próprio tempo presente são agora palcos do não pertencimento, do deslocamento e da resistência.

Percebe-se, portanto, o quanto o dramaturgo russo aprofundou radicalmente o movimento do qual a virada do século XIX para o século XX tornaria-se palco: o de tematizar abertamente a experiência do tempo e, simultaneamente, desafiar a própria forma da experiência no drama. Um movimento problemático e produtivo. Problemático, porque desestabilizou formas seculares, que ainda serviam de referência e baliza crítica; produtivo, porque pôs a própria forma dramática e a possibilidade de representação em xeque e demandou formas que iluminassem, de modo mais potente, as experiências temporais reais. Não à toa, seria com o próprio Tchékhov que Stanislávski desenvolveria boa parte dos preceitos de seu sistema, que incluiria, mais tarde, a mescla da experiência temporal vivida e experimentada pelos atores à temporalidade do texto dramatúrgico e cênico.

$\mathrm{O}$ drama tornou-se, assim, mais permeável à temporalidade de outros gêneros e linguagens, deslocando sua própria centralidade e criando as condições para que um texto se tornasse "apto" à cena - não porque precisou utilizar os recursos típicos de um texto dramático, mas porque oferecia material válido para discussão. Daí a conclusão de Theresia Birkenhauer, na esteira de Heiner Müller, de que a partir daí o teatro seria menos uma máquina de expressões e mais uma "relação temporal, na qual os mais diversos tempos estão presentes simultaneamente". ${ }^{29}$ Desse modo, interessa pouco uma homogeneidade entre o tempo do espectador e o tempo da ação da intriga; muito mais produtiva é a capacidade do

\footnotetext{
${ }^{28}$ Aqui, tomo o conceito de empréstimo de Siegfried KRACAUER. The Last Things Before the Last.

${ }^{29}$ BIRKENHAUER. O tempo do texto no teatro, p. 3.
} 
teatro moderno e contemporâneo de reconhecer e negociar essas múltiplas temporalidades que habitam o fenômeno cênico. Na trilha de Tchékhov, o teatro contemporâneo pode demonstrar, assim, uma disposição radical à temporalidade do Outro e a resistência à temporalidade única do Capital (hoje globalmente acelerada, falsamente positiva e substancialmente esvaziada), que insiste em esmagar as diferentes dimensões da vida humana.

\section{Referências}

ARISTÓTELES. Poética. Organon. Politica. Constituição de Atenas. Tradução de Baby Abrão. São Paulo: Nova Cultural, 1999.

BARRY, J. Dramatic Structure: the shaping of experience. Berkeley: University of California Press, 1970.

BIRKENHAUER, T. O tempo do texto no teatro. Cena, Porto Alegre, n. 11, p. 1-15, 2012.

GLASS, V. Antonio Candido inaugura biblioteca do MST e fala da força da instrução. Carta Maior, São Paulo, 8 ago. 2006. Disponível em: <https://www.cartamaior.com.br/?/Editoria/Movimentos-Sociais/ Antonio-Candido-inaugura-biblioteca-do-MST-e-fala-da-forca-dainstrucao/2/11075>. Acesso em: 11 fev. 2019.

KATÁEV, V. B. If Only We Could Know: An Interpretation of Chekhov. Chicago: Ivan R. Dee, 2002.

KRACAUER, S. History: The Last Things Before the Last. Oxford: Oxford University Press, 1969.

KUNTZ, H. Belo animal (morte do). In: SARRAZAC, J-P. (org.). Léxico do Drama Moderno e Contemporâneo. São Paulo: Cosac \& Naify, 2005. p. 41-43.

MAETERLINCK, M. Os Cegos. Tradução de Lara Biasoli Moler, p. 3-11.

PAVIS, P. Dicionário de Teatro. São Paulo: Editora Perspectiva, 2008.

PRIGOGINE, I. The End of Certainty. Nova York: Free Press, 1997.

ROSENFELD, A. O teatro épico. São Paulo: Editora Perspectiva, 2004. 
Aletria, Belo Horizonte, v. 29, n. 1, p. 73-89, 2019

ROUBINE, J-J. Introdução às Grandes Teorias do Teatro. São Paulo: Jorge Zahar Editor, 2000.

STEWART, W. Time Structure in Drama: Goethe's Sturm Und Drang Plays. Amsterdam: Editions Rodopi, 1978.

SZONDI, P. Teoria do Drama Burguês. São Paulo: Cosac \& Naify, 2004.

SZONDI, P. Teoria do Drama Moderno. São Paulo: Cosac \& Naify, 2001.

TCHÉKHOV, A. A Gaivota / Tio Vânia. Tradução de Gabor Aranyi. São Paulo: Veredas, 2003.

TCHÉKHOV, A. A Gaivota. Tradução de Rubens Figueiredo. São Paulo: Cosac \& Naify, 2004.

TCHÉKHOV, A. Ivánov. Tradução de Arlete Cavaliere e Eduardo Tolentino de Araújo. São Paulo: Edusp, 1998.

TCHÉKHOV, A. Três Irmãs/ O Jardim das Cerejeiras. Tradução de Gabor Aranyi. São Paulo: Veredas, 2006.

TURNER, C. J. G. Time in Chekhov's Tri Sestry. Canadian Slavonic Papers. Abingdon, v. 28, n. 1, p. 64 -79, mar. 1986.

UBERSFELD, Anne. L'École du Spectateur. Paris: Éditions Sociales, 1981.

UBERSFELD. Para ler o teatro. São Paulo: Editora Perspectiva, 2013.

Recebido em: 1ํ de outubro de 2018.

Aprovado em: 25 de janeiro de 2019. 